\title{
Penerapan Ornamen Melayu Deli pada Rancangan Desain Interior Masjid Pasujudan Jannatun Naim
}

\author{
Irwansyah $^{* 1}$, Heldiansyah ${ }^{2}$ \\ ${ }^{1,2}$,Program Studi Desain Interior Fakultas Seni dan Desain Universitas Potensi Utama \\ E-mail:*1irw.syah23@gmail.com, ${ }^{2}$ heldiansyah18@gmail.com
}

\begin{abstract}
Abstrak
Beragamnya suku, budaya dan agama di Indonesia membuat bentuk rumah tinggal, fasilitas umum, kantor dan juga tempat/rumah ibadah dibangun dengan menyesuaikan suku dan budaya yang ada di daerah masing, seperti bangunan Istana Maimoon dibangun dengan bentuk dan unsur budaya melayu deli dan percampuran budaya asing (Eropah). Bagitu juga dengan bangunan masjid yang dibangun sesuai dengan budaya, suku dan adat istiadat dari daerah setempat. Dengan hal ini, penulis melakukan penelitian dengan merancang sebuah desain interior masjid dengan menerapkan ornamen melayu deli. Dalam penelitian ini juga menggunakan metode kombinasi yaitu antara metode kualitatif dengan metode kuantitatif, dengan tujuan agar mendapatkan data yang valid, komprehensif, obyektif dan reliable. Tahap setelah mendapatkan data dari metode tersebut, peneliti juga mengunakan proses desain, dimana proses analisis dan proses sintesis. Penerapan ornamen Melayu Deli pada interior Masjid Pasujudan Jannatun Naim dapat menambah unsur budaya sehingga dapat memberikan kesan bersih, suci, sejuk, luas, dan nyaman serta menjaga sebuah keharmonisan kepada penggunanya.
\end{abstract}

Kata Kunci : Interior, Masjid, Melayu Deli, dan Ornamen

\begin{abstract}
The diversity of ethnicities, cultures and religions in Indonesia makes housing, public facilities, offices as well as places / houses of worship built according to the ethnicity and culture in their respective areas, such as the Maimoon Palace building built with the form and elements of Malay deli culture and a mixture of cultures. foreign (Europe). Likewise with the mosque building which was built in accordance with the culture, ethnicity and customs of the local area. With this, the authors conducted research by designing a mosque interior design by applying Malay deli ornaments. In this study also used a combination method, namely qualitative methods with quantitative methods, with the aim of obtaining valid, comprehensive, objective and reliable data. The stage after obtaining data from this method, the researcher also uses the design process, which is the analysis process and the synthesis process. The application of Malay Deli ornaments to the interior of the Pasujudan Jannatun Naim Mosque can add cultural elements so that it can give the impression of being clean, holy, cool, spacious, and comfortable and maintaining harmony to its users.
\end{abstract}

Keywords: Interior, Mosque, Melayu Deli, and Ornaments 


\section{PENDAHULUAN}

Indonesia memiliki beragam suku, budaya dan agama. Dimana agama islam menjadi agama mayoritas di Indonesia, karena $\pm 86 \%$ penduduk Indonesia memeluk Agama Islam. Sistem demokrasi yang ada di Indonesia membuat negara ini memberikan kebebasan kepada masyarakat untuk bebas memilih agama dan kepercayaannya sendiri. Dengan Konstitusi yang ada di Indonesia membuat negara Indonesia menetapkan bahwa keyakinan harus dilandaskan kepada Ketuhanan Yang Maha Esa (kondisi tersebut juga merupakan prinsip pertama Pancasila, yaitu filosofi negara Indonesia yang dibeberkan presiden Soekarno pada tahun 1945. Beragamnya agama yang ada di Indonesia dikarenakan adanya penyebaran dan pengenalan dari bangsa lain. Sehingga Indonesia memiliki 6 agama resmi atau yang diakui yaitu:
a. Islam
b. Kristen
c. Katolik
d. Hindu
e. Budha
f. Konghucu

Beragam agama beragam juga tempat/rumah ibadah agama, seperti; agama Kristen dan Katolik tempat ibadahnya Gereja, agama Budha tempat ibadahnya Vihara, agama Hindu tempat ibadahnya Pura, agama Konghucu tempat ibadahnya Klenteng, dan agama mayoritas di Indonesia juga memiliki tempat/rumah ibadah yang dinamakan/disebut dengan Masjid untuk agama Islam. Dimana masjid adalah tempat/rumah ibadah bagi umat islam dalam melaksanakan ibadah, yaitu sholat.

Dengan beragamnya suku, budaya dan agama di Indonesia membuat bentuk rumah tinggal, fasilitas umum, kantor dan juga tempat/rumah ibadah dibangun dengan menyesuaikan suku dan budaya yang ada di daerah masing, seperti bangunan Istana Maimoon dibangun dengan bentuk dan unsur budaya melayu deli dan percampuran budaya asing (Eropah). Bagitu juga dengan bangunan masjid yang dibangun sesuai dengan budaya, suku dan adat istiadat dari daerah setempat. Dengan hal ini, penulis melakukan penelitian dengan merancang sebuah desain interior masjid dengan menerapkan ornamen melayu deli.

\section{I.1. Melayu Deli}

Suku Melayu Deli adalah salah satu suku Melayu yang mendiami kabupaten Deli Serdang. Penyebaran meliputi kota Medan, Deli Tua, daerah pesisir, pinggiran sungai Deli dan Labuhan. Di kota Medan suku Melayu Deli banyak menempati daerah pinggiran kota. Populasi suku Melayu diperkirakan lebih dari 2 juta orang.

Suku Melayu Deli berbicara dalam bahasa Melayu Deli. Sekilas bahasa Melayu Deli mirip dengan bahasa Indonesia dengan logat Melayu yang kental dan pengucapan yang lebih singkat dan cepat. Pada beberapa tempat, bahasa Melayu Deli, menggunakan isyarat, perumpamaan atau kiasan yang terwujud dalam pantun tersebut.

Melayu Deli memiliki bentuk, symbol dan ornament tersendiri. Budaya Melayu Deli dapat dilihat dari peninggalan yang ada di tengah-tengah Kota Medan yaitu Istana Maimoon. Istana Maimoon adalah peninggalan dari kerajaan Melayu Deli, dimana 
kerajaan dipimpin oleh seorang Sultan. Bentuk yang indah yang dihasilkan dari perpaduan budaya Melayu Deli dan Eropah membuat kesan tersendiri pada bangunan tersebut. Penerapan ornament Melayu Deli juga baik dan memiliki arti.

\section{I.2. Ornamen}

Ornament adalah sebuah karya seni yang dapat diterapkan pada hiasan-hiasan dinding yang berfungsi sebagai penambah keindahan dekorasi dindi, benda ataupun produk-produk lain. Ornament ditambahkan atau diletakkan juga dapat sebagai sebuah identitas budaya tertentu. Contoh penerapan ornament budaya Betawi pada sebuah interior rumah, dapat menandakan bahwa penghuni rumah tersebut bersuku Betawi, walaupun hal tersebut belum benar adanya.

Dalam sebuah buku yang berjudul Ornamen Nusantara karya Sunaryo (2009 : 3) menyebutkan penerapan sebuah hiasan pada produk, itu disebut dengan ornamen. Dimana penempatan hiasan pada produk dapat semakin menambah indah produk tersebut setelah diberikan sebuah ornamen. Penerapan ornament juga banyak digunakan pada bangunan Arsitektur dan Desain Interior. Dimana penerapan yang dimaksud adalah agar sebuah bangunan tersebut mempunyai nilai budaya sesuai dengan budaya setempat.

Metode yang digunakan dalam penelitian ini adalah metode kualitatif, dimana metode ini digunakan untuk menganalisa permasalahan melalui mengumpulkan data, menyusun data dan melakukan klarifikasi data-data yang ada. Data yang dimaksud adalah data yang relevan yang memang dapat menunjang penelitian ini.

Dalam penelitian ini juga menggunakan metode kombinasi yaitu antara metode kualitatif dengan metode kuantitatif, dengan tujuan agar mendapatkan data yang valid, komprehensif, obyektif dan reliable. Tahap setelah mendapatkan data dari metode tersebut, peneliti juga mengunakan proses desain, dimana proses analisis dan proses sintesis

Tahapan pertama yang dilakukan adalah proses analisis, dimana pada tahapan ini dilakukan sebuah proses Analisa pada permasalahan dari data-data yang sudah di dapatkan. Proses analisis ini biasa disebut tahapan programming. Setelah dilakukan Analisa maka dilanjutkan dengan proses sintesis atau disebut dengan tahapan desain. Tahapan ini merupakan hasil dari tahapan programming yang nantinya dibuatkan beberapa alternatif solusi permasalahan yang ada. Alternatif yang terbaik adalah alternatif yang dapat memecahkan permasalahan yang kemudian alternatif tersebut yang akan dipilih.

\section{I.3. Masjid Pasujudan Jannatun Naim}

Menurut Sofyan Syafri Harahap dalam bukunya yang berjudul "Manajeman Masjid" (1996) mengatakan Masjid adalah Masjid merupakan salah satu unsur penting dalam struktur masyarakat Islam. Masjid bagi umat Islam memiliki makna yang besar dalam kehidupan, baik makna fisik maupun makna spiritual. Kata masjid itu sendiri berasal dari kata sajada-yasjudu-masjidan (tempat sujud). Pada penelitian ini, peneliti melakukan perancangan interior Masjid Pasujudan Jannatun Naim yang terletak di Jl. Kawat 7, Gg Wakaf, Tj Mulia Hilir, Kecamatan Medan Deli, Medan, Sumatera Utara. Lokasi ini strategis karena dekat dengan pemukiman warga dan memiliki akses jalan yang cukup baik. Dan mayoritas masyarakat yang ada disekitar Masjid Pasujudan Jannatun Naim adalah suku Melayu. 


\section{STUDI LITERATUR}

Dalam beribadah bukan hanya ingin mencari pahalanya saja tetapi bagaimana seseorang merasakan khusyuk dalam beribadah, nyaman dan aman dalam menunaikan kewajibannya. Maka perlu dibuat sebuah rancangan konsep yang aman dan nyaman untuk digunakan ketika menjalakan kewajiban dalam agama. Rancangan ruang yang nyaman dan aman dengan ditambahnya sebuah penerapan budaya seperti ornamen Melayu Deli akan menambah nilai-nilai estetik yang sangat menawan. Maka dengan itu diperlukan sebuah acuan dalam melakukan penelitian ini. Acuan-acuan tersebut dilihat, dibandingkan dan dibedakan dari penelitian-penelitian sebelumnya yang berkaitan dengan penelitian ini. Ayesya Ainun Nabila, dkk (2020) dalam penelitiannya yang berjudul "Penerapan Ornamen Khas Betawi Dalam Interior Masjid Raya Kh. Hasyim Asyari Jakarta Barat" dalam penelitian ini melakukan penyelusuran dan Analisa ornament khas Betawi pada bangunan-bangunan masjid, dimana ornament tersebut bukan hanya diterapkan pada rumah-rumah adat Betawi saja tetapi juga dapat diterapkan pada bangunan-bangunan lain. Laksmi Kusuma Wardani, Arinta Prilla Gustinantari (2008) dengan judul penelitian "Penerapan Elemen Hias Pada Interior Masjid Al Akbar Surabaya" mengatakan dalam penelitiannya bahwa penerapan elemen hias pada interior Masjid Al Akbar Surabaya sudah sesuai dengan aturan-aturan ajaran islam. Dalam penelitian ini juga melakukan proses penyelusuran dan Analisa untuk menemukan kesesuai perancangan dan penerapan elemen hias atau ornament yang digunakan pada masjid tersebut. Dari kedua penelitian tersebut menjadi pijakan bagi peneliti dalam melakukan penerapan ornamen Melayu Deli dalam merancang interior Masjid Pasujudan Jannatun Naim agar sesuai dengan aturan atau ajaran islam, nyaman dan aman Ketika beribadah dan indah ketika dipandang.

\section{PEMBAHASAN \\ III. 1. Ornamen Melayu Deli}

Ada banyak jenis ornamen Melayu Deli yang bisa ditemukan pada bangunanbangunan heritage yang ada di kota Medan. Salah satu bangunan yang menggunakan unsur ornamen melayu pada arsitektur dan interiornya adalah bangunan peninggalan kesultanan Deli yaitu Istana Maimoon. Istana Maimoon adalah sebuah kerajaan Melayu Deli yang di pimpin oleh seorang Sultan. Bangunan Istana Maimoon dirancang dengan konsep perpaduan budaya eropah dengan budaya Melayu Deli. Dimana pada eksterior dan interior dari bangunan terdapat ornamen-ornamen yang berasal dari budaya Melayu deli. Unsur ornamen Melayu Deli yang sering ditemukan pada bangunan heritage kota Medan adalah ornamen tumbuh-tumbuhan, hewan, alam dan pucuk rebung. Berikut jenis ornamen Melayu Deli yang Sering ditemukan, yaitu : 
Tabel 1. Ornamen Melayu Deli

(sumber : Ayu Kartini - 2014)

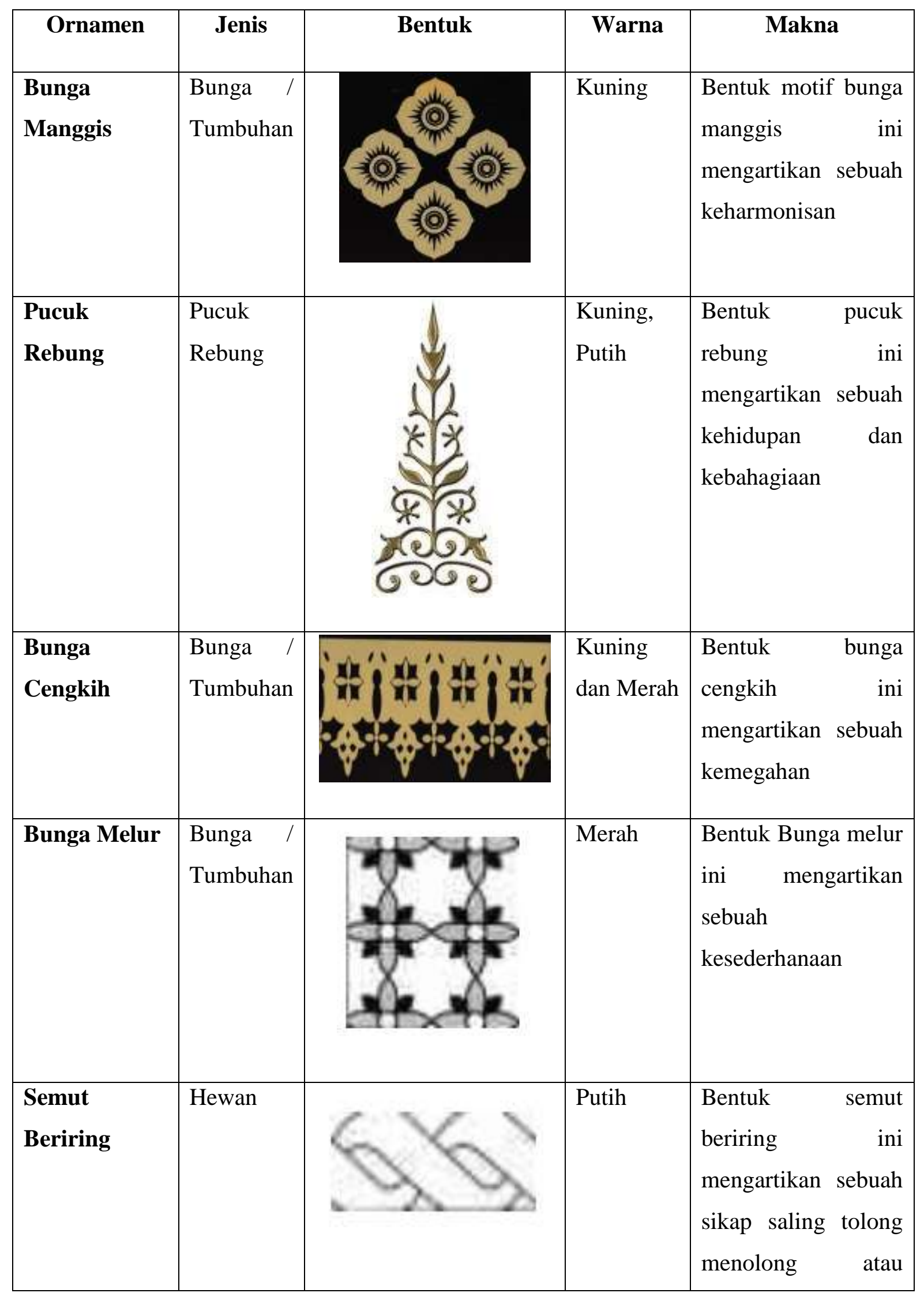




\begin{tabular}{|c|c|c|c|c|}
\hline & & & & bekerjasama \\
\hline Itik Sekawan & Hewan & & $\begin{array}{l}\text { Hijau dan } \\
\text { Kuning }\end{array}$ & $\begin{array}{l}\text { Bentuk itik sekawan } \\
\text { ini mengartikan } \\
\text { sebuah } \\
\text { atau persahabatan }\end{array}$ \\
\hline $\begin{array}{l}\text { Lebah } \\
\text { Bergantung }\end{array}$ & Hewan & & $\begin{array}{l}\text { Kuning, } \\
\text { Hijau }\end{array}$ & $\begin{array}{lr}\text { Bentuk lebah } \\
\text { bergantung } \\
\text { mengartikan } \\
\text { manisnya sebuah } \\
\text { kehidupan dalam } \\
\text { berumah tangga }\end{array}$ \\
\hline Kaluk Pakis & Tumbuhan & & $\begin{array}{l}\text { Putih, } \\
\text { kuning }\end{array}$ & 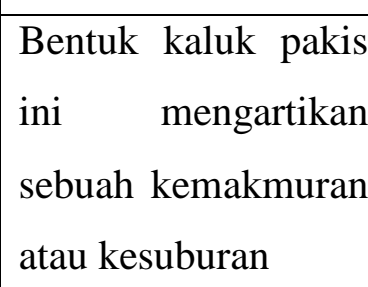 \\
\hline $\begin{array}{l}\text { Bunga } \\
\text { Kundur }\end{array}$ & $\begin{array}{l}\text { Bunga / } \\
\text { Tumbuhan }\end{array}$ & & $\begin{array}{l}\text { Hitam, } \\
\text { Hijau, } \\
\text { Kuning }\end{array}$ & $\begin{array}{lr}\text { Bentuk } & \text { bunga } \\
\text { kundru } & \text { ini } \\
\text { mengartikan } & \text { sebuah } \\
\text { nilai kasih sayang }\end{array}$ \\
\hline
\end{tabular}

\section{III.2. Penerapan Ornamen pada Interior Masjid}

Sebagai upaya untuk mempertahankan budaya atau kearifan lokal, peneliti melakukan peracangan sebuah bangunan tempat ibadah yaitu masjid dengan menerapkan unsur-unsur budaya. Berikut adalah layout dari bangunan Masjid lantai 1 dan lantai 2; 


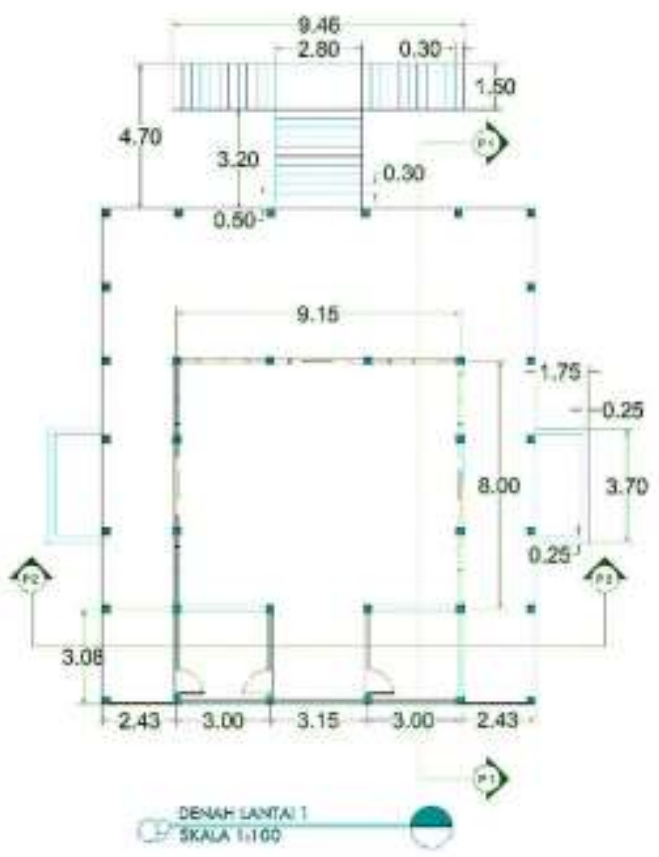

Gambar 1. Layout lantai 1 Masjid (sumber : Dokumentasi Pribadi - 2020)

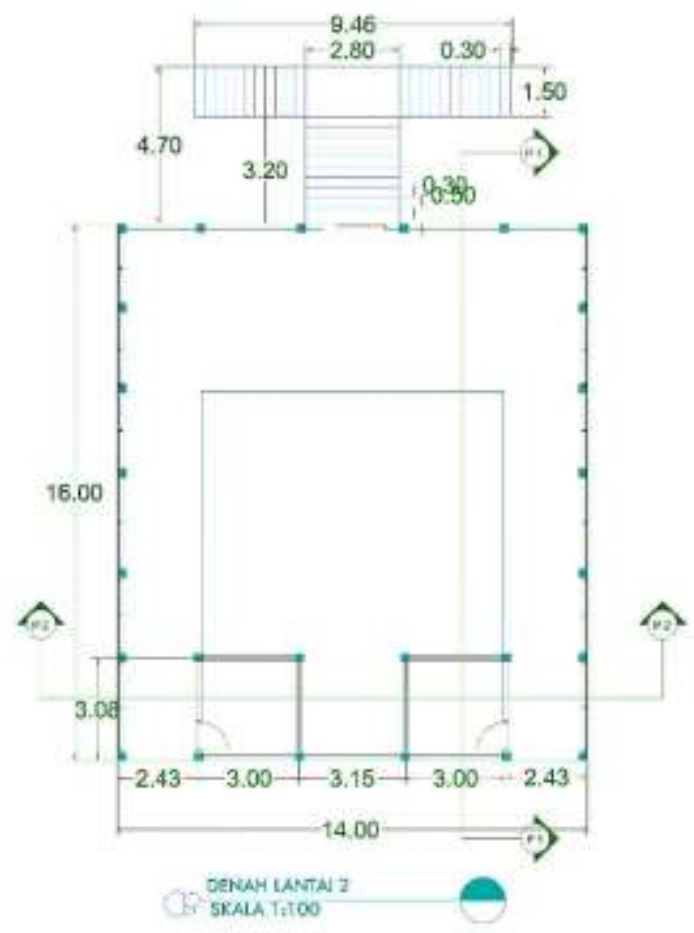

Gambar 1. Layout lantai 2 Masjid (sumber : Dokumentasi Pribadi - 2020)

Dimana elemen pembentuk dalam rancangan ruang interior adalah lantai, dinding, plafon, dan berbagai bukaan serta elemen pengisi ruang. 
1. Lantai

Tabel 2. Kriteria Alternatif Lantai Masjid

(sumber : Dokumentasi Pribadi - 2020)

\begin{tabular}{|l|c|c|c|c|}
\hline Kriteria/Jenis & $\begin{array}{c}\text { Mudah } \\
\text { Dibersihkan }\end{array}$ & $\begin{array}{c}\text { Pilihan } \\
\text { Warna }\end{array}$ & Estetika & $\begin{array}{c}\text { Mengkilat } \\
\text { dan Bersih }\end{array}$ \\
\hline $\begin{array}{l}\text { Keramik } \\
\text { Putih }\end{array}$ & + & - & - & + \\
\hline Parket & - & + & + & - \\
\hline Granit & + & + & + & + \\
\hline
\end{tabular}

Alternatif terpilih: Granit dengan menerapakan ornamen bunga manggis yang bermakna dan bertujuan untuk menampilkan kesan bersih dan luas pada lantai masjid dan menjaga sebuah keharmonisan.

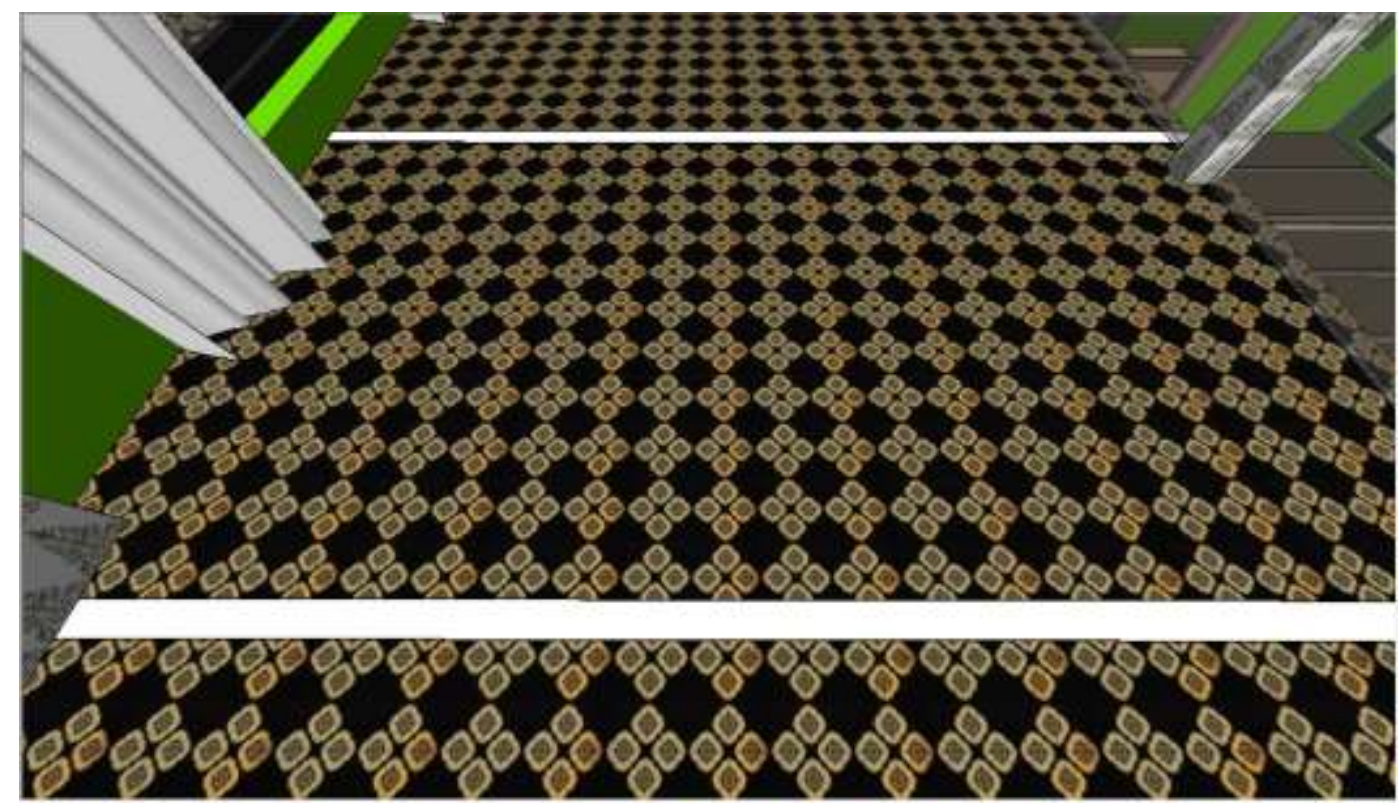

Gambar 3. Lantai Garnit dengan Menerapkan Motif Bunga Manggis (sumber : Dokumentasi Pribadi - 2020)

2. Dinding

Tabel 2. Kriteria Alternatif Dinding Masjid

(sumber : Dokumentasi Pribadi - 2020)

\begin{tabular}{|l|c|c|c|c|}
\hline Kriteria/Jenis & $\begin{array}{c}\text { Kesan } \\
\text { Hangat }\end{array}$ & $\begin{array}{c}\text { Pilihan } \\
\text { Warna }\end{array}$ & $\begin{array}{c}\text { Perawatan } \\
\text { Mudah }\end{array}$ & $\begin{array}{c}\text { Sesuai } \\
\text { konsep }\end{array}$ \\
\hline Walpaper & - & + & - & - \\
\hline Kayu & + & + & - & + \\
\hline Cat & + & + & + & + \\
\hline
\end{tabular}


Alternatif terpilih: Cat berwarna hijau dan diberikan motif pucuk rebung bertutujuan agar interior masjid memberikan kesan bersih, suci, sejuk, luas, dan nyaman serta kepada penggunanya.

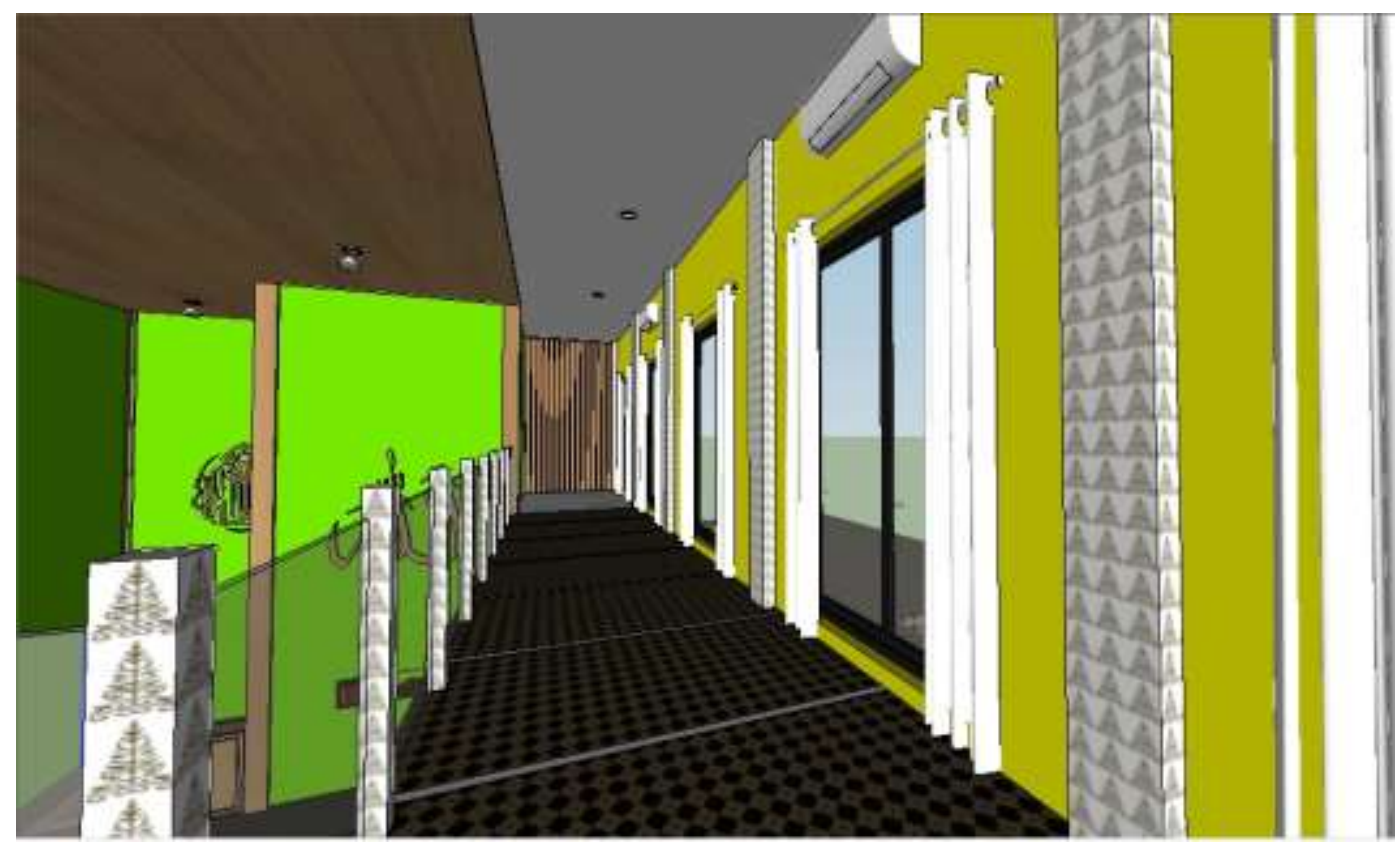

Gambar 4. Dinding dengan Cat hijau dan menerapkan Ornamen Pucuk Rebung (sumber : Dokumentasi Pribadi - 2020)

3. Plafon

Tabel 3. Kriteria Alternatif Plafon Masjid

(sumber : Dokumentasi Pribadi - 2020)

\begin{tabular}{|l|c|c|c|c|}
\hline Kriteria/Jenis & $\begin{array}{c}\text { Model } \\
\text { beragam }\end{array}$ & Kuat & $\begin{array}{c}\text { Perawatan } \\
\text { Mudah }\end{array}$ & keindahan \\
\hline Gypsum & + & + & + & + \\
\hline triplek & - & - & + & - \\
\hline $\begin{array}{l}\text { Kayu } \\
\text { lambersering }\end{array}$ & - & + & + & + \\
\hline
\end{tabular}

Alternatif terpilih: gypsum berwarna putih yang memberikan kesan bersih pada langit-langit masjid dan juga disesuaikan dengan warna lantai dan dinding. 


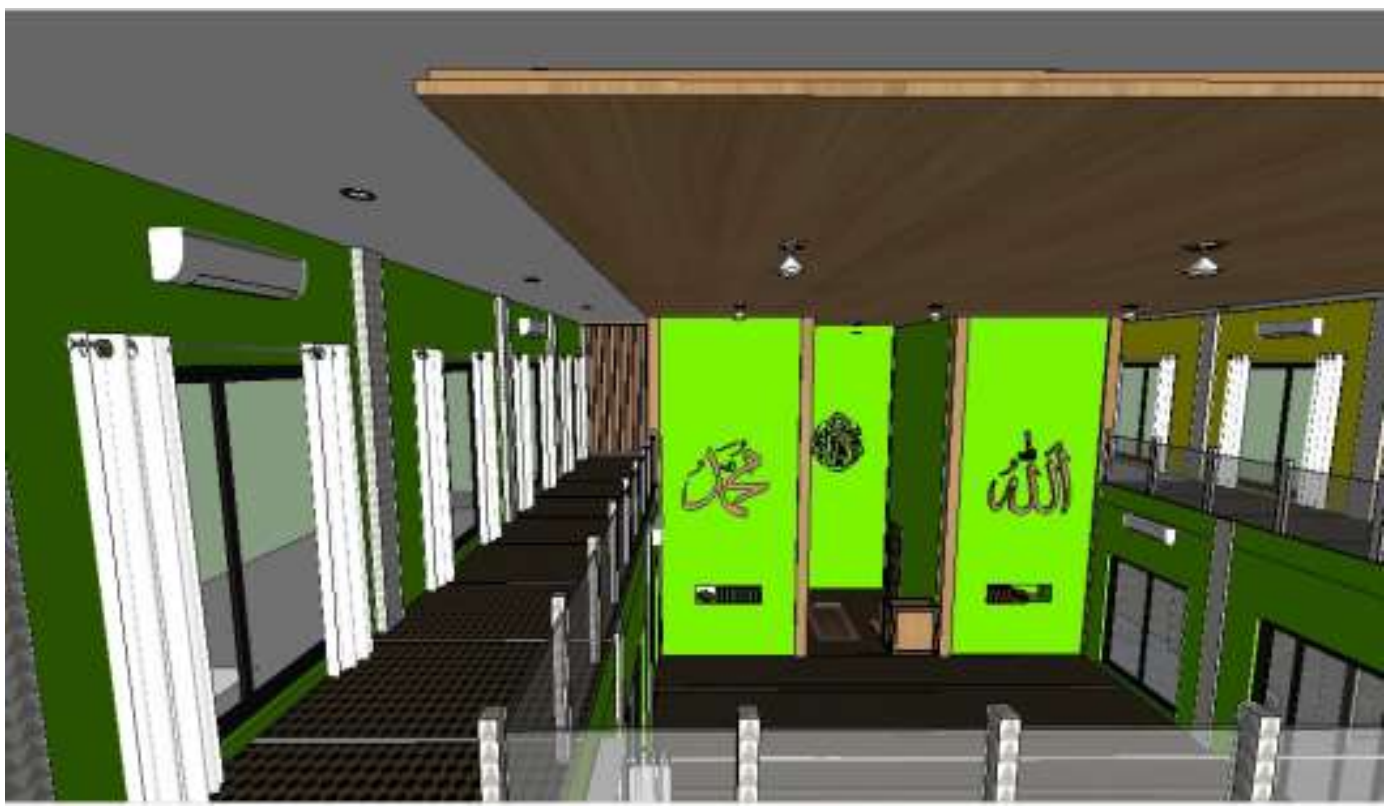

Gambar 5. Plafon dengan material gypsum berwarna putih (sumber : Dokumentasi Pribadi - 2020)

\section{Elemen Pengisi Ruang Masjid}

Perabot yang digunakan pada perancangan bangunan masjid ini terdiri dari adalah:

a. Mimbar adalah tempat yang disediakan untuk khatib menyampaikan khutbah.

b. Pengeras suara (speaker) yang digunakan untuk proses ibadah seperti mengumandangkan azan, khutbah dan lainnya.

\section{Tata Kondisi Ruang Masjid}

Tata kondisi ruang Masjid Pasujudan Jannatun Naim adalah sistem penggunaan pencahayaan dan penghawaan. Sistem pencahayaan pada masjid ini adalah menggunakan sistem pencahayaan buatan dan alami. Pencahayaan alami yang digunakan adalah membuat banyak jendela kaca sehingga dapat memanfaatkan cahaya matahari yang nantinya dapat menghemat energi pada siang hari. Sedangkan pencahayaan buatan yang digunakan adalah menggunakan hidden light, lampu downlight dan lampu gantung. Dimana sistem pencahayaan buatan ini untuk :

a. Dari segi Fungsional : mendukung kegunaan dan aktivitas dalam ruang

b. Dari segi Kualitas : Daya tahan lampu yang lama dan pencahayaan yang baik

c. Dari segi Estetika : Mendukung suasana, keindahan ruangan dan menonjolkan material yang digunakan

Sesuai kebutuhan ruang interior dan kegunaannya rancangan yang dibuat dalam penelitian ini terlihat seperti penerapan ornament Melayu Deli dengan warna lembut, islami dan penerapan kayu menunjukkan unsur budaya dan alami pada interior Masjid Pasujudan Jannatun Naim ini. 


\section{KESIMPULAN}

Ornamen Melayu Deli adalah salah satu unsur budaya Sumatera Utara yang memang banyak ditemukan pada bangunan-bangunan heritage Kota Medan. Namun unsur ornamen Melayu Deli ini dapat juga diterapkan pada bangunan-bangunan rumah bahkan tempat ibadah, salah satunya adalah Masjid Pasujudan Jannatun Naim. Dimana penerapan beberapa ornamen Melayu Deli pada interior Masjid Pasujudan Jannatun Naim tidak hanya untuk tempat beribadah saja tetapi juga dapat menambah unsur budaya sehingga dapat memberikan kesan bersih, suci, sejuk, luas, dan nyaman serta menjaga sebuah keharmonisan kepada penggunanya.

\section{DAFTAR PUSTAKA}

[1]. Dorno, Jeksi. (2014). Bentuk Dan Makna Simbolik Ornamen Ukir Pada Interior Masjid Gedhe Yogyakarta. Skripsi. Fakultas Bahasa dan Seni, Pendidikan Seni Rupa, Universitas Negeri Yogyakarta

[2]. Kartini, Ayu. (2014). Analisis Penerapan Ornamen Bernuansa Melayu Ditinjau Dari Bentuk Dan Warna Di Kota Medan. Skripsi. Fakultas Bahasa Dan Seni, Pendidikan Seni Rupa, Universitas Negeri Medan

[3]. Moleong, Lexy J. (2002). Metodologi Penelitian Kualitatif. Bandung: PT. Remaja Rosdakarya.

[4]. Nabila, A. A., Septiana, A. S., Nabila, G., \& Damayanti, R. A. (2020). Penerapan Ornamen Khas Betawi dalam Interior Masjid Raya KH. Hasyim Asyari Jakarta Barat. Jurnal Dimensi Seni Rupa dan Desain, 16 (2), 101-112.

[5]. Sofyan, S.H. (1996). Manajemen Masjid. Hal. 26. Jogyakarta: Bhakti Prima Rasa.

[6]. Sunaryo, A. (2009). Ornamen Nusantara: kajian khusus tentang ornamen Indonesia. Dahara Prize.

[7]. Supriyadi, Bambang. (2008). Kajian Ornamen Pada Mesjid Bersejarah Kawasan Pantura Jawa Tengah. Jurnal Ilmiah Perancangan Kota dan Permukiman. Vol. 7 No. 2 Juni 2008.

[8]. Prayogi, R. (2021). Analisis Ornamen Pada Bangunan Masjid Al Osmani Medan. PROPORSI: Jurnal Desain, Multimedia dan Industri Kreatif, 5(2), 217226.

[9]. Wardani, L. K., \& Gustinantari, A. P. (2008). Penerapan Elemen Hias pada Interior Masjid Al Akbar Surabaya. Dimensi Interior, 6(2).

[10]. Wardono, Prabu. (2011). Catatan Kuliah - Desain Interior III. Hal. 25. Bandung. Institut Teknologi Bandung. 